\title{
The Influence of the AWJM Working Parameters on Manufactured Surfaces Microgeometry
}

\author{
Iulian Patirnac ${ }^{1,},{ }^{*}$ Razvan George Ripeanu ${ }^{1}$, and Eugen Laudacescu ${ }^{1}$ \\ ${ }^{1}$ University Petroleum-Gas of Ploiesti, Mechanical Engineering Department, 100680 Bucharest Blvd., \\ Romania
}

\begin{abstract}
The aim of this paper is to make a research in order to analyze the modification of the microgeometry parameters of AWJ machined surfaces for a ductile material used in oilfield and petrochemical equipment. Experimental research was performed on waterjet cutting machine model YCWJ-380-1520 using pre-establish working conditions. The SURTRONIC 3+ device was used in order to measure the microgeometry characteristics of the machined surfaces. Experimental tests were performed regarding some values for: material thickness, working feed-rate and standoff distance. The obtained outcomes highlighted that there are three zones on cutting surfaces for thick material and only two zones for thin materials. There are a lot of profile parameters provided by the software and there were taken into account only the average roughness (Ra) and average waviness (Wa). For each of those two parameters were accomplished graphical representation for every working parameters in order to establish an analytical dependence between them. The outcomes which were obtained are polynomial four order equations of average roughness and waviness according to standoff distance. The analytical relations obtained give us the possibility to estimate the average roughness of the surfaces related to thickness, feed-rate and standoff distance.
\end{abstract}

\section{Description of AWJ machine and working parameters}

The aim of this paper is the study of microgeometry obtained on the kerf surfaces generated by the AWJ process, machining a soft alloyed steel used in oilfield and petrochemical equipment. The study of kerf microgeometry is made in the framework of the experiments using AWJ machine WUXI YCWJ-380-1520, presented in fig.1. This machine is made up by the follows: machine table (known as machine bath), CNC controller using CAD/CAM software, high pressure system, cutting head and abrasive particules controling system.

The cutting head of AWJ machine is made up by high pressure nozzle (also called water nozzle), mixing tube and main cutting head body. Regarding the types of the machine active parts, the flowing parameters used in the AWJ prosess are shown in Table 1 and the abrasive material used by WJ machine is Garnet $80 \mathrm{Mesh}$. According to the experiment by measuring the volume of water filled in a specified period of time, it was obtained that the average velocity at the outlet of water nozzle is about $622.35 \mathrm{~m} / \mathrm{s}$.

${ }^{*}$ Corresponding author: ipatirnac@gmail.com 

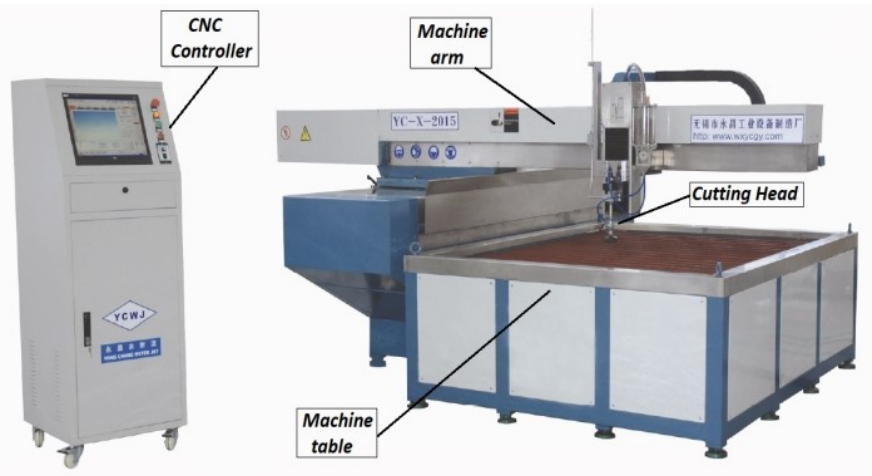

Fig. 1. AWJ machine WUXI YCWJ-380-1520, [1].

At the outlet of the focusing tube, the maximum value of water velocity obtained by CFD simulation on the active parts of AWJ machine is about $187.5 \mathrm{~m} / \mathrm{s}$. According to some authors $[2,3]$, the water velocity at the end of the mixing tube is between 120 and $400 \mathrm{~m} / \mathrm{s}$, depending on the flow parameters.

Table 1. Flowing parameters used in AWJ process

\begin{tabular}{|l|c|}
\hline Water nozzle diameter, [mm]: & 0.25 \\
\hline Mixing tube diameter, [mm]: & 0.76 \\
\hline Water flow rate, [1/min]: & 1.83 \\
\hline Abrasive flow rate, [g/s]: & 3.543 \\
\hline
\end{tabular}

The geometry of the material sample subjected to AWJ machining it is presented in fig.2. That shape was been adopted taking into account the capabilities of AWJ Machine and the mechanical characteristics of the material subjected to the cutting. The initial raw material was steel plate having $40 \mathrm{~mm}$ thickness and the two other dimensions were obtained by using cutting conventional machining (milling) to the dimensions $\mathrm{L}_{\mathrm{p}} \times \mathrm{l}_{\mathrm{p}}=$ $280 \mathrm{~mm} \times 240 \mathrm{~mm}$. In order to highlight the waterjet influence on the material, it was adopted four stages of piece thickness, but due to limitation of material width, it was adopted that every thickness stage to be $58 \mathrm{~mm}$ width $\left(l_{t r}\right)$.

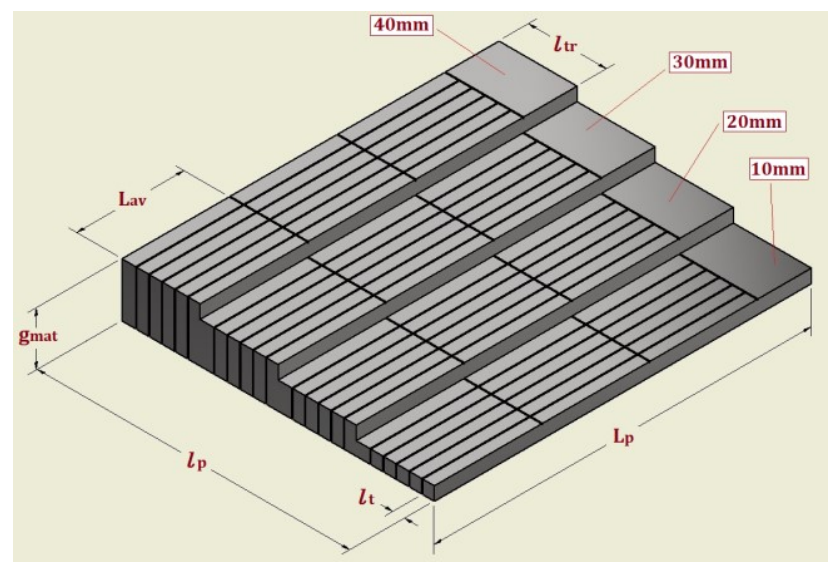

Fig. 2. Schematic of the workpiece machined on AWJ. 
In order to emphasize the effects of AWJ technological parameters on the material characteristics and microgeometry of kerfs surfaces, it was adopted the working parameters presented in Table 2. In order that jet of water has no influence on the neighboring kerfs, it was made that distance between them $\left(l_{t}\right)$ to be at least $9 \mathrm{~mm}$ and the length $L_{a v}$ to machine one feed rate stage is set to $80 \mathrm{~mm}$.

Table 2. Working parameters used for experiments

\begin{tabular}{|l|l|}
\hline Stage thickness, $h[\mathrm{~mm}]:$ & $10 ; 20 ; 30 ; 40$ \\
\hline Standoff distance $\delta,[\mathrm{mm}]:$ & $1.0 ; 1.5 ; 2.0 ; 2.5 ; 3.0$ \\
\hline Working feedrate $f,[\mathrm{~mm} / \mathrm{min}]:$ & $4 ; 6 ; 9$ \\
\hline
\end{tabular}

The material used inside of the experiment is P275NL2, that means a soft alloyed steel used for high pressure equipment, containing $0.17 \% \mathrm{C}$ and the yield strength is about $275 \mathrm{MPa}$.

\section{Investigation of surface microgeometry}

It was used SURTRONIC 3+ profilometer in order to measure the kerf microgeometry and the obtained values are processed using TalyProfile Lite 2.1 software. The profile diagram of microgeometry resulted after the program process it is shown in fig.3. The 2D parameters can be calculated respectively on the raw profile $(\mathrm{P})$, or after filtering, on the roughness profile $(\mathrm{R})$ or on the waviness profile $(\mathrm{W})$. For each parameter, the type of filtering and the cut-off to be used are defined. According to ISO 4287 standard, some parameters can be defined on sampling length and others on assessment length. The sample length is set on $2.5 \mathrm{~mm}$ for each measurement.

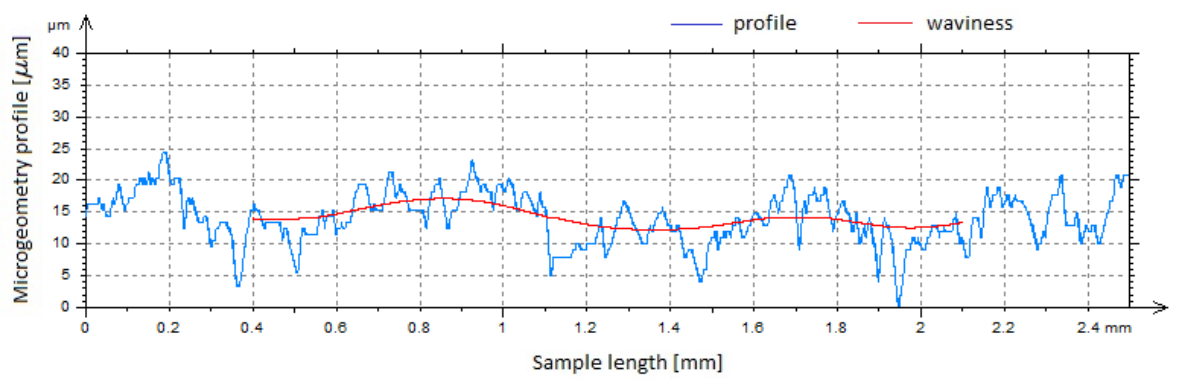

Fig. 3. Profile diagram generated by the software.

There are a lot of parameters which can define a surface microgeometry. In this study are processed only three of them as it follows below, for roughness profile (R) and waviness profile (W). It is made the sense that $\mathrm{X}$ prefix is to be replaced by $\mathrm{P}, \mathrm{R}$ or $\mathrm{W}$ according to the needs [4-6].

$\mathrm{Xa}$ : arithmetic mean of the assessed profile. It is defined by the expression (1) and the result is expressed in length unit of the $\mathrm{Z}$ axis.

$$
\mathrm{Xa}=\frac{1}{\mathrm{lb}} \sum_{0}^{\mathrm{lb}}|\mathrm{Z}(\mathrm{x})|
$$

In the above relation, $\mathrm{Z}(\mathrm{x})$ represents the height measured on the vertical axis $[\mu \mathrm{m}] ; l b$ represents the sampling length. 
$\mathrm{Xt}$ : total height of the profile on the evaluation length. It has the inconvenience of being very sensible at abnormal points (deep holes or extreme peaks).

$\mathrm{Xz}$ : maximum height of the profile within a sampling length. It is defined as: $\mathrm{Xz}=\mathrm{Xp}+\mathrm{Xv}$, where: $\mathrm{Xp}$ represents the maximum profile peak height within the sampling length, and $\mathrm{Xv}$ represents the maximum profile valley depth within a sampling length.

In the case of small thicknesses there are two zones on the kerf surface: the superior zone (S) situated at the entrance of waterjet to the material, and the inferior zone $(\mathrm{J})$ situated at the waterjet exit to the material, as can be shown in fig.4. At the high thicknesses (over $20 \mathrm{~mm}$ ), it can be distinguished a central zone (C) placed between the two others. According to some authors [7], there are two mechanisms of wear which rule the AWJ process along jet trajectory through the material. So that, the upper zone is characterized by cutting wear and the lower zone by deformation wear.
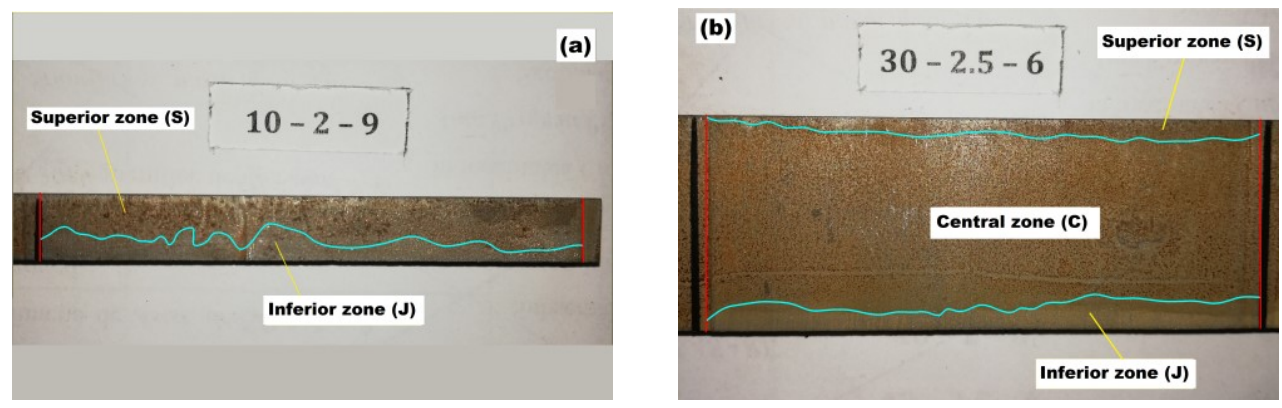

Fig. 4. Kerf surface zones. (a) $10 \mathrm{~mm}$ thickness; (b) $30 \mathrm{~mm}$ thickness.

In example, in fig. 5 it is presented the graphical representation of average roughness (Ra) for the upper zone of the kerf surfaces machined with $4 \mathrm{~mm} / \mathrm{min}$. It can be noticed that all four graphical forms present a waveshape of average roughness of surfaces along to the regarded standoff distances. In this case, the maxim value of average roughness is $5.46 \mu \mathrm{m}$ and it is obtained cutting the $30 \mathrm{~mm}$ material thickness at $3 \mathrm{~mm}$ standoff distance. The lower value is $1.31 \mu \mathrm{m}$ obtained at $1.5 \mathrm{~mm}$ of standoff distance cutting the same material thickness. The highest values of (Ra) are obtained for $10 \mathrm{~mm}$ of material thickness and the lowest for $30 \mathrm{~mm}$, exception for $3 \mathrm{~mm}$ standoff where was obtained the maxim value of this case.

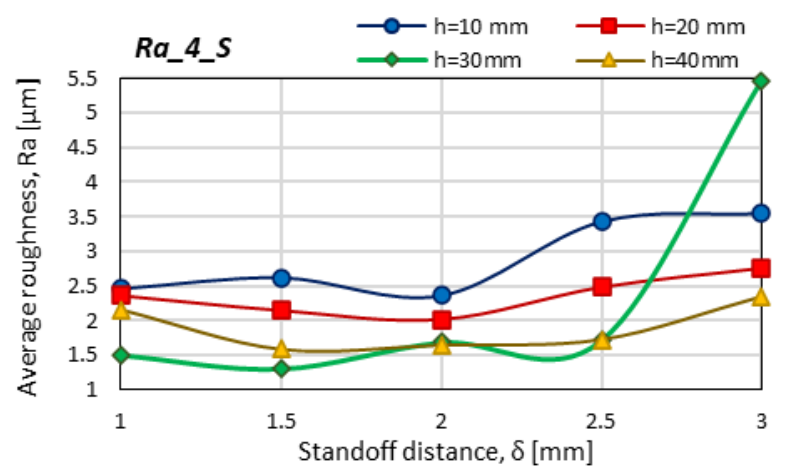

Fig. 5. Roughness (Ra), feed-rate $4 \mathrm{~mm} / \mathrm{min}$, superior zone (S).

\section{Analytical investigation of kerf profile}

Due to average roughness $(\mathrm{Ra})$ is indicated on ISO standard drawings, and for a shorter period of lapping (in case of machine parts are manufactured through such a procedure), it 
is recommended that $\mathrm{Ra}$ to be $(1.5 \ldots 2) \mathrm{Wa}$. It was searched to find some laws to express these two parameters on the entire height of the kerf. Due to there are many zones with different profiles on kerf surface, it was made the average of $\mathrm{Ra}$ and Wa using relation (2), where Xa represents the average value of either rouhness or waviness, $X a_{i}$ is the roughness or waviness measured in the specified zone on the kerf, $n$ is the number of zones.

$$
\mathrm{Xa}=\frac{\sum X a_{i}}{n}
$$

From above, results that there are 24 charts and equation to debate in that study. In order to simplify the analysis, it is debated only roughness ( $\mathrm{Ra}$ ) and waviness (Wa) it is debated in this paper, both in case of $10 \mathrm{~mm}$ material thickness and $4 \mathrm{~mm} / \mathrm{min}$ working feed rate, in order to simplify the analysis. The others have a similarity to these two cases. As can be observed in fig.6, the average roughness along the height of the kerf has an alternat variation showing two peaks at $1.5 \mathrm{~mm}$ and $3 \mathrm{~mm}$ standoff distance. The maximum value in the case of roughness is $2.99 \mu \mathrm{m}$ and it is obtained at $3 \mathrm{~mm}$ standoff distance. The minimum value is about $2.54 \mu \mathrm{m}$ and it is obtained at $2 \mathrm{~mm}$ of standoff.

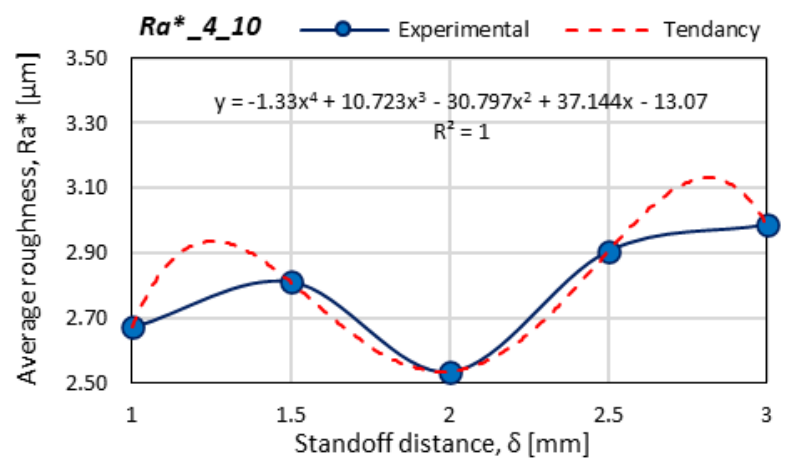

Fig. 6. Roughness distribution for (Ra) $4 \mathrm{~mm} / \mathrm{min}$ working feed-rate and $10 \mathrm{~mm}$ material thickness.

Any resulted equation was obtained using interpolation method and the factor $\mathrm{R}^{2}=1$ for one another. That means any experimental point is fitted on the trend curve for any standoff distance regarded. As the result of the analyses, both average roughness $\mathrm{Ra}$ and average waviness $\mathrm{Wa}$, can be expressed as an equation, generally, written in the form of fourth order equation given by expression (3), for each material thickness and feed rate range.

$$
\mathrm{Xa}=\mathrm{A} \cdot \delta^{4}+\mathrm{B} \cdot \delta^{3}+\mathrm{C} \cdot \delta^{2}+\mathrm{D} \cdot \delta+\mathrm{E}
$$

In the above expression, Xa represents either average roughness or waviness, $\delta$ represents the standoff distance and coefficients $A, B, C, D, E$ are given in Table 3, only for $10 \mathrm{~mm}$ working piece thickness and each feed rate.

Table 3. Coefficients of expression (3) for $10 \mathrm{~mm}$ material thickness

\begin{tabular}{|c|c|c|c|c|c|c|}
\hline \multirow{2}{*}{$\begin{array}{c}\text { Feed-rate } \\
{[\mathbf{m m} / \mathbf{m i n}]}\end{array}$} & \multirow{2}{*}{$\begin{array}{c}\text { Parameter } \\
{[\boldsymbol{\mu \mathbf { m } ]}}\end{array}$} & \multicolumn{5}{|c|}{ Coefficient } \\
\cline { 3 - 7 } & $\mathrm{A}$ & $\mathbf{B}$ & $\mathbf{C}$ & $\mathbf{D}$ & $\mathbf{E}$ \\
\hline \multirow{2}{*}{4} & $\mathrm{Ra}$ & -1.33 & 10.723 & -30.797 & 37.144 & -13.07 \\
\cline { 2 - 7 } & $\mathrm{Wa}$ & -1.278 & 10.419 & -31.037 & 40.151 & -17.39 \\
\hline \multirow{2}{*}{6} & $\mathrm{Ra}$ & -0.5833 & 5.1567 & -16.074 & 20.891 & -6.785 \\
\cline { 2 - 7 } & $\mathrm{Wa}$ & -2.4177 & 19.55 & -56.544 & 68.458 & -27.098 \\
\hline \multirow{2}{*}{9} & $\mathrm{Ra}$ & 0.8333 & -6.1267 & 16.142 & -17.883 & 9.68 \\
\cline { 2 - 7 } & $\mathrm{Wa}$ & 3.25 & -25.583 & 71.467 & -83.134 & 35.635 \\
\hline
\end{tabular}


Similar to the above table were obtained the coefficients for the other stages like $20 \mathrm{~mm}$, $30 \mathrm{~mm}$ and $40 \mathrm{~mm}$. Knowing the laws which rule the surface microgeometry it is created a software application in order to estimate either roughness $(\mathrm{Ra})$ or waviness $(\mathrm{Wa})$. The interface of the program is shown in fig.7 and was created using Visual Studio 2019.

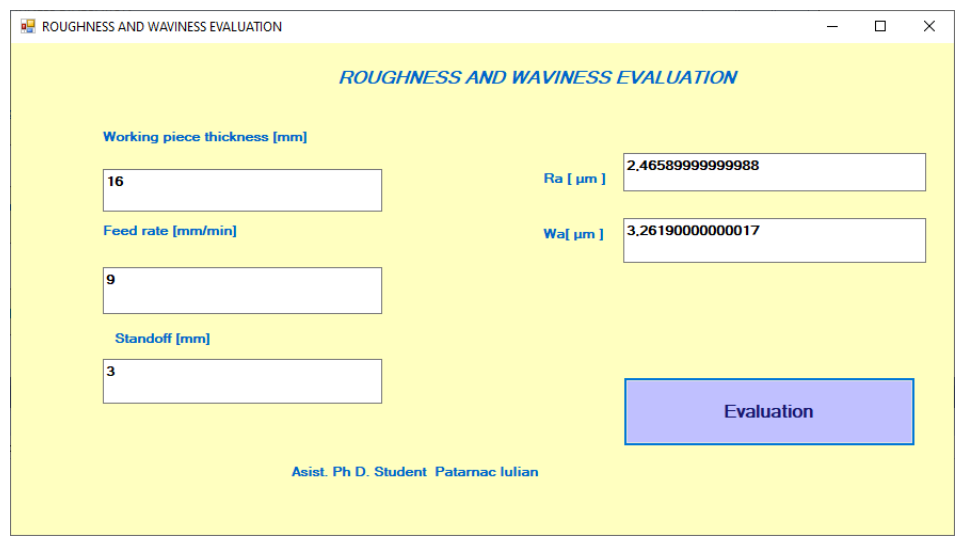

Fig. 7. The panel of the software application.

\section{Conclusion}

For thin metallic materials (up to 15 or $20 \mathrm{~mm}$ ) machined by AWJ process there are two distinguished zones on the kerf surface, along the jet trajectory. Over 20mm thickness, can be noticed that there are three zones and their areas have a random variation. The maximum values of average roughness $(\mathrm{Ra})$ are obtained on the inferior zone and the minimum values are obtained on the superior zone. According to some authors, the upper zone is featured by a smooth area and the lower zone by a rough surface.

According to the outcomes obtained in this analysis, it can be concluded that average roughness and waviness can be estimated using de equations developed in this paper, inside of AWJ machining process used for the steel P275NL2. With the aid of these equations, it is possible to create a software program in order to calculate either roughness or waviness, for a specified thickness, feed rate or standoff distance, whose values are inside the intervals which are taken into account on this paper.

\section{References}

1. https://chinawaterjet.com/ycwaterjet/products/full-set-yc-water-jet-cutting-machine/ (accessed: may, 2019)

2. N. H. Kamarudin, A.K. Prasada, A. Azhari, IOP Conf. Ser.: Mater. Sci. Eng. 114, 5 (2016)

3. X. Long, X. Ruan, Q. Liu, Z. Chen, S. Xue, Z. Wu, Pow. Tech. 314, 637 (2017)

4. UNE EN ISO 4287:1999/A1:2010 Geometrical Product Specifications (GPS) - Surface texture: Profile method - Terms, definitions and surface texture parameters Amendment 1.

5. UNE EN ISO 4288:1998: GPS - Surface texture: Profile method - Rules and procedures for the assessment of surface texture.

6. SURTRONIC 3+ technical booklet

7. G. Cosansu, C. Cogun, J. Mater. Sci. Eng. 26, 2372 (2012) 